\title{
Blog da Quarentena: uma proposta de produção textual, leitura interlocutiva e análise linguística
}

\section{Quarantine Blog: a proposal for text production, interlocutive reading and linguistic analysis}

Alice Ribeiro Dionizio1

\begin{abstract}
Resumo
Este trabalho objetiva apresentar uma breve narrativa e uma breve reflexão acerca de uma prática de ensino levada a cabo durante o momento pandêmico em que vivemos. Dessa forma, realizamos essa atividade durante as Atividades Pedagógicas não Presenciais (ANPs) em um Instituto Federal de Educação, Ciência e Tecnologia do Estado de Santa Catarina. A atividade de ensino foi nomeada "Blog da Quarentena" e objetivou oferecer aos alunos um espaço para a escrita de si, considerando suas impressões e vivências diante da pandemia. Essa escrita de si foi permeada por diferentes gêneros, como o meme, 0 diário, a carta etc. Além disso, construímos uma prática de leitura interlocutiva porque acreditamos que a prática de leitura dos textos dos alunos precisa ser pensada como um processo dialógico e não apenas de revisão e correção. Por fim, construímos junto com os alunos uma prática de análise linguística sobre concordância e pontuação, uma vez que durante a leitura interlocutiva identificamos essas questões como pontos a serem melhorados na produção de muitos estudantes.
\end{abstract}

Palavras-chave: Atividades Pedagógicas não Presenciais. Blog da Quarentena. Prática de Análise Linguística.

\begin{abstract}
This work aims to present a brief narrative and a brief reflection on a teaching practice carried out during the pandemic moment in which we live. Thus, we carried out this activity during the Non-Attendance Pedagogical Activities (ANPs) at a Federal Institute of Education, Science and Technology in the state of Santa Catarina. The teaching activity was named "Quarantine's Blog" and aimed to offer students a space for self-writing, considering their impressions and experiences in the face of the pandemic. This writing itself was permeated by different genres, such as the meme, the diary, the letter etc. In addition, we built an interlocutive reading practice because we believe that the reading practice of students' texts needs to be thought of as a dialogical process and not just one of revision and correction. Finally, together with the students, we built a practice of linguistic analysis on agreement and punctuation, since during the interlocutive reading we identified these issues as points to be improved in the production of many students.
\end{abstract}

Keywords: Non-Attendance Pedagogical Activities. Quarentine's Blog. Word. Practice of Linguistic Analysis.

\section{Introdução}

Este trabalho objetiva apresentar uma experiência de ensino de Língua Portuguesa com base na Prática de Análise Linguística a partir da Prática de Produção de Textos. Para tanto, faz-se necessário (re)enunciar os já ditos (GERALDI, 2012; GERALDI, 1997; FRANCHI, 2006a; FRANCHI, 2006b; FRANCO; ACOSTA PEREIRA; COSTA-HÜBES, 2019 entre outros) para que a partir dessa relação dialógica, possamos construir frutíferas considerações sobre a temática.

\footnotetext{
${ }_{1}^{1}$ Mestra em Estudos Linguísticos. Instituto Federal de Santa Catarina (Alice Ribeiro Dionizio, Chapecó, Santa Catarina, Brasil). Orcid: https://orcid.org/0000-0003-3337-8889 E-mail: alice.dionizio@ifsc.edu.br
} 
As discussões envolvendo a Prática de Análise Linguística (doravante PAL) foram introduzidas no contexto brasileiro por Geraldi (2012 [1984]). Na obra intitulada "O texto na sala de aula", o pesquisador apresenta questionamentos cruciais acerca do ensino de Língua Portuguesa. Segundo ele, o professor precisa ter muito claro quais são os seus objetivos ao ensinar ao mesmo passo que precisa definir a qual concepção de linguagem se filia. Nesse sentido, Geraldi constrói suas reflexões a partir de uma concepção de linguagem como forma de interação, pois, para ele, "a língua só tem existência no jogo que se joga na sociedade, na interação. E é no interior do seu funcionamento que se pode procurar estabelecer as regras de tal jogo." (GERALDI, 2012, p. 42).

A prática de ensino aqui narrada ocorreu no contexto pandêmico e, portanto, foi realizada durante 0 ensino remoto - entendido como aquele em que tanto professores quanto alunos não estão presencialmente no mesmo espaço físico, mas que utilizam recursos tecnológicos para a mediação pedagógica. As atividades foram realizadas com alunos do ensino técnico integrado ao ensino médio de uma instituição federal de ensino e congregam práticas que consideram a importância da escrita de si, com toda a subjetividade que isso pode envolver, bem como a importância do trabalho com gêneros nas aulas de língua portuguesa.

\section{As contribuições de Geraldi e Franchi para o ensino de Língua Portuguesa}

Qualquer discussão que tenha por temática o que chamamos de PAL precisa considerar inicialmente as contribuições feitas por Franchi e Geraldi. Franchi (2006a), ao abordar a relação entre texto e gramática, aponta para o fato de que saber gramática vai muito além de conhecer todas as normas advogadas pela gramática tradicional. Para 0 autor, saber gramática corresponde a utilizá-la efetivamente na produção de textos. Dessa forma, percebemos um alargamento na concepção de gramática que é crucial para compreender a PAL.

A noção de unidades básicas de ensino - prática de leitura de textos, prática de escrita de textos e prática de análise linguística - é apresentada por Geraldi no texto "Portos de Passagem" (1997 [1991]). Segundo o pesquisador, essas atividades não devem ser pensadas de forma separada, pois funcionam como um continuum e estão diretamente relacionadas. $O$ interessante dessa proposta feita por Geraldi, ainda nos anos 80, é o fato de que o pesquisador propõe uma inversão: não se deve valorizar o ensino gramatical a partir de sentenças e frases soltas, mas é preciso considerar textos reais que são construídos a partir de diferentes vozes que dialogam entre si. Ou seja, é preciso compreender os textos como enunciados que carregam em si diferentes maneiras de dizer e se relacionar com a sociedade. 
Nesta perspectiva, Geraldi aponta também para a possibilidade de se utilizar a PAL como instrumento de correção e de autocorreção dos textos produzidos pelos alunos. Assim posta, a PAL seria utilizada para mostrar aos alunos diferentes formas de dizer (o que está diretamente relacionado ao processo de estilização dos textos - expansão, substituição, apagamento etc.), compreendendo para isso atividades linguísticas e epilinguísticas. As atividades metalinguísticas, por sua vez, serviriam como suporte para as análises e para o ensino de gramática (reflexões sobre a língua). Temos, portanto, ações com a língua, sobre a língua e da língua. Importante mencionar também que o primeiro a utilizar a nomenclatura de atividades linguísticas, epilinguísticas e metalinguísticas foi Franchi - orientador de Geraldi - no seu conhecido texto "Criatividade e Gramática" de 1991.

No final da década de 90, o governo brasileiro publicou os Parâmetros Curriculares Nacionais para servirem de suporte aos professores de todo o país e de diferentes áreas de atuação. No caso da disciplina de Língua Portuguesa, percebe-se uma influência direta dos postulados de Geraldi (e de Franchi), bem como de outras áreas de estudo (como a Teoria dos Gêneros, da Linguística Textual, da Sociolinguística Aplicada, da Psicolinguística Aplicada etc.). Esse movimento apresenta uma mudança de enfoque nas aulas de língua, pois valoriza o texto (considerando-o como um enunciado relativamente estável e organizado em diferentes gêneros do discurso), a língua a partir de um viés social e as diferentes práticas com a língua (leitura, produção e análise linguística).

\section{A Prática de Análise Linguística de Perspectiva Dialógica}

A Análise Dialógica do Discurso (doravante ADD) é uma área de estudo genuinamente brasileira que busca relacionar os estudos dialógicos do Círculo de Bakhtin (BAKHTIN, 1979; BAKHTIN; VOLOCHÍNOV, 1929; MEVIÉDEV, 1928 entre outros) com a perspectiva da Linguística Aplicada e, de forma mais abrangente, com as Ciências Humanas. Nesse sentido, a ADD também se debruça para compreender e propor práticas de ensino que valorizem a Prática de Análise Linguística de perspectiva Dialógica (doravante ALD), pois

\footnotetext{
O estudo do enunciado nos permite compreender as relações verbo-axiológicas do sujeito que, em determinadas bases cronotópicas e ideológicas, sustentam sua intenção enunciativa, validando, assim, seu projeto de dizer. É no enunciado, portanto, que a realidade do sujeito e da língua(gem) se apresenta em sua totalidade (uma relativa totalidade). (FRANCO; ACOSTA PEREIRA; COSTA-HÜBES, 2019, p. 282, destaques no original).
}

A ALD é pensada a partir alguns conceitos fundamentais, como sujeito, discurso e enunciado. A concepção de sujeito, por exemplo, compreende alguém que que é atravessado pelo outro ao mesmo 
passo que é um ser valorativo, ideológico e imerso na alteridade. O discurso, por sua vez, pode ser entendido como a língua viva e o enunciado como sua materialização. Quando o enunciado se torna estável, tem-se o gênero do discurso. (FRANCO; ACOSTA PEREIRA; COSTA-HÜBES, 2019).

Esses conceitos são fundamentais para compreender a ALD que apresenta uma mudança de postura diante da Prática de Análise Linguística: se com Geraldi temos uma proposta que busca diagnosticar as fragilidades da produção textuais dos alunos, na ALD tem-se um alargamento da proposta ao se incluir uma análise que considere as relações internas (o interior do gênero - como forma, estrutura, conteúdo temático etc.) bem como a orientação externa (tempo, espaço, campo de atividade de onde o enunciado emerge etc.) (OLIVEIRA; POLATO, 2015).

Nesse sentido, a Análise Linguística realizada dentro das aulas de Língua Portuguesa compreende uma abordagem que pode ser realizada não apenas depois da prática de produção de textos (é possível inclui-la já na prática de leitura), envolvendo uma reflexão criteriosa sobre os diferentes aspectos presentes no texto (especialmente os que estão relacionados ao cronotopo e à axiologia, à autoria e ao estilo, ao conteúdo temático e ao tema etc.). Dessa forma, a ALD inclui textos produzidos pelos alunos mas não só, uma vez que objetiva levar os estudantes a refletirem sobre as construções linguísticas utilizadas, aos valores implícitos dos enunciados, à formação ideológica daquele que produz esses enunciados (considerando também o aspecto responsivo e dialógico, ou seja, a construção ideológica e axiológica do interlocutor a que se destina o texto), bem como as condições sociais de produção que interferem diretamente na construção interna dos enunciados.

\section{Narrando a prática, praticando a narrativa}

Entendemos aqui que a escrita funciona como uma importante ferramenta para a reflexão de si e como prática social. Seja na literatura ou em outros campos da sociedade, escrever é uma prática social que envolve, além dos recursos linguísticos, contextos que influenciam diretamente no que dizer e como dizer. Esse é o caso da pandemia que assola o mundo desde 2020. Dessa forma, essa proposta de ensino tinha como objetivo levar os alunos e alunas a refletirem, a partir da prática escrita, sobre sua relação com a pandemia de modo a expressarem suas subjetividades e impressões diante de uma realidade totalmente atípica e, até então, inimaginável.

A proposta foi chamada de "Blog de Quarentena" e os estudantes foram convidados a produzirem diferentes gêneros discursivos dentro desse blog: (i) mini diário da quarentena; (ii) registro escrito de um relato oral; (iii) carta/e-mail para o "eu do futuro sem coronavírus"; (iv) meme da quarentena; 
e (v) vídeo minuto "O que eu aprendi com a quarentena?". Nesta prática, não buscamos "ensinar" aos alunos o que é um blog, ou um meme, ou mesmo uma carta. Em outras palavras, não se trata de teorizar sobre o gênero, mas sim incentivar a produção escrita, considerando o interlocutor (que no caso da carta/e-mail, por exemplo, é o próprio ‘eu do futuro').

Os critérios de avaliação foram explicitados já no momento da proposta: (i) pontualidade na entrega; (ii) produções realizadas; (iii) questões de ordem linguística; (iv) criatividade e originalidade; e (iv) layout da ferramenta utilizada. Por se tratar de uma proposta multimodal, os alunos foram orientados a utilizarem a plataforma que melhor respondesse às suas necessidades. Alguns optaram pelo Instagram e outros pelas plataformas disponíveis para a construção de blogs (como blogspot.com).

A seguir, apresentamos ao leitor alguns exemplos das produções dos alunos. Importante mencionar que se tratam de publicações públicas veiculadas na internet, o que dá um teor de visibilidade e realidade para o que foi produzido. Sabemos que muitas vezes as produções escritas de nossos alunos ficam encerradas nas "paredes" da sala de aula e que, por isso mesmo, somos (nós professores) os únicos leitores desses textos. Quando incentivamos que os alunos escrevam "para fora", as possibilidades de interação são reais e a prática social se efetiva.

Cada aluno encontrou sua forma de apresentar seu blog. Alguns foram diretos e disseram que se tratava de um trabalho escolar (nomeando, inclusive, a disciplina e a professora), mas outros foram um pouco além: usando um formato comum nos antigos blogs, e até um pouco de ironia, definiram o blog como espaço de discussão e reflexão pessoais. Trazemos aqui um exemplo:

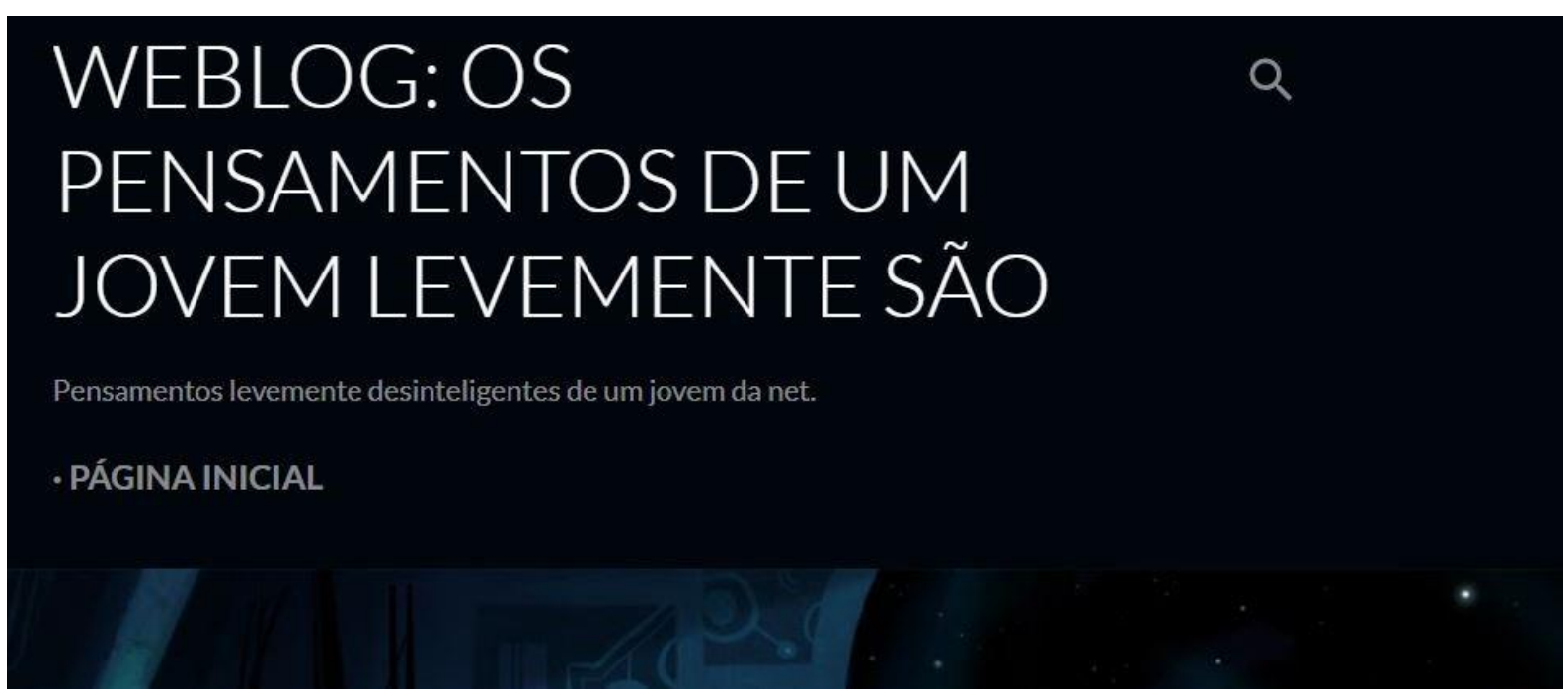

Figura 1. Apresentação blog

Fonte. Blog estudante 
Interessante observar como o estudante se posiciona diante do blog, há uma forte indicação de autoria e de subjetividade, pois há uma tentativa de definir-se a si mesmo ao mesmo passo que define o que é o seu blog e o que o leitor encontrará nessa ferramenta.

Como se tratam de espaços reais da internet, uma prática que adotamos ao ler esses materiais foi o que chamamos aqui de "leitura interlocutiva", ou seja, utilizamos os recursos de comentários para nos fazermos presentes diante do que estávamos lendo. Assim como nossos alunos se propuseram a escrever sobre suas impressões, subjetividades e experiências, buscamos também oferecer um feedback ativo diante dessas singularidades. A seguir apresentamos um exemplo dessa "leitura interlocutiva":

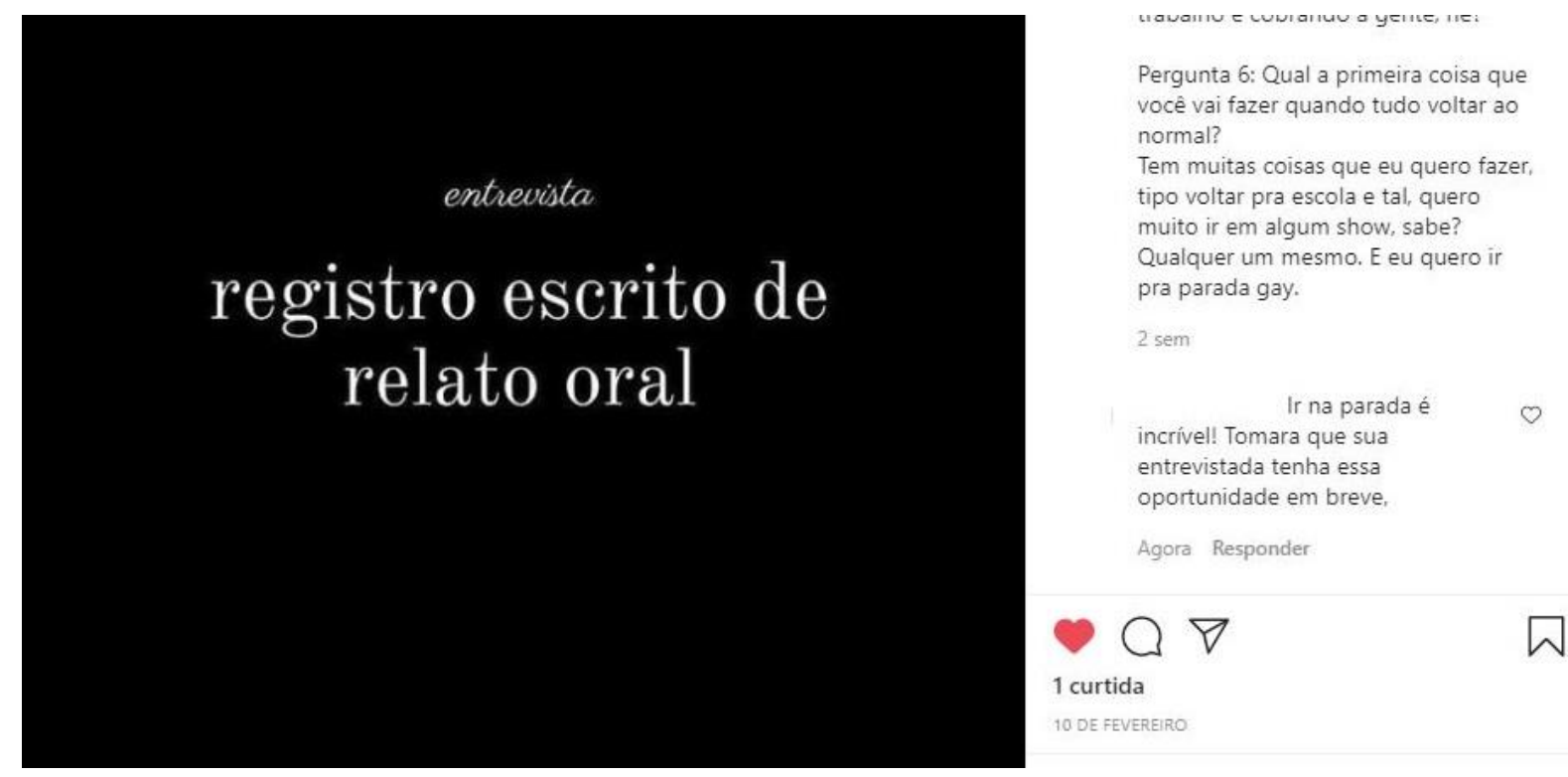

Figura 2. Exemplo de leitura interlocutiva Fonte. Blog estudante

Ao apresentar respostas efetivas às produções feitas pelos alunos, posicionamo-nos como verdadeiros interlocutores dentro da constituição axiológica dos enunciados. Além disso, possibilitamos uma prática de linguagem permeada por atividades linguísticas, ou seja, a língua em uso. Nesse sentido, a constituição do dizer de nossos estudantes acaba por encontrar em nossas respostas o interlocutor que tanto esperam. Mas importante: não se trata de um comentário de correção ou de apontamentos de melhorias, são comentários dentro de uma prática de interlocução, a partir dos quais nos posicionamos também como sujeitos que possuem algo a dizer através da linguagem.

Dentro da proposta do Blog da Quarentena, percebemos que muitos alunos utilizaram esta atividade como um verdadeiro espaço de fala de si, ou seja, de suas experiências e vivências dentro do 
contexto pandêmico. Essa atividade reflexiva diante do vivenciado nesse período tão inóspito era um de nossos objetivos iniciais, o que revela a importância dessas práticas dentro da escola. Sabemos que as mudanças trazidas pela pandemia refletem diretamente em todos, mas em especial nos jovens adolescentes que, muitas vezes, perdem sua maior referência de sociabilidade: a escola. Nesse sentido, muitos foram os relatos acerca de ansiedades, medos, inseguranças e descontentamento diante do vivido. Trata-se de uma escrita inteiramente subjetiva que revela formas de ver e de experienciar 0 mundo.

Mas, afinal, como podemos compreender essas práticas de escrita dentro da ALD? Nosso argumento é que ao oportunizarmos aos nossos alunos uma escrita sincera de si, reconhecemos nele um sujeito que é atravessado pelo outro (e por outros dizeres) da mesma forma que quando oferecemos a ele nossa leitura interlocutiva, reconhecemo-nos dentro da alteridade e reconhecemos o discurso deste outro que também nos auxilia no processo da nossa própria constituição. Reconhecer que o sujeito é ideológico e atravessado pelo outro é reconhecer, portanto, que tanto professor quanto aluno se (retro)constituituem nas práticas diárias de sala de aula.

Diante da potência dessas narrativas, gostaríamos de destacar um último exemplo. Trata-se de um excerto do gênero "carta/e-mail para o 'eu do futuro sem coronavírus'”:

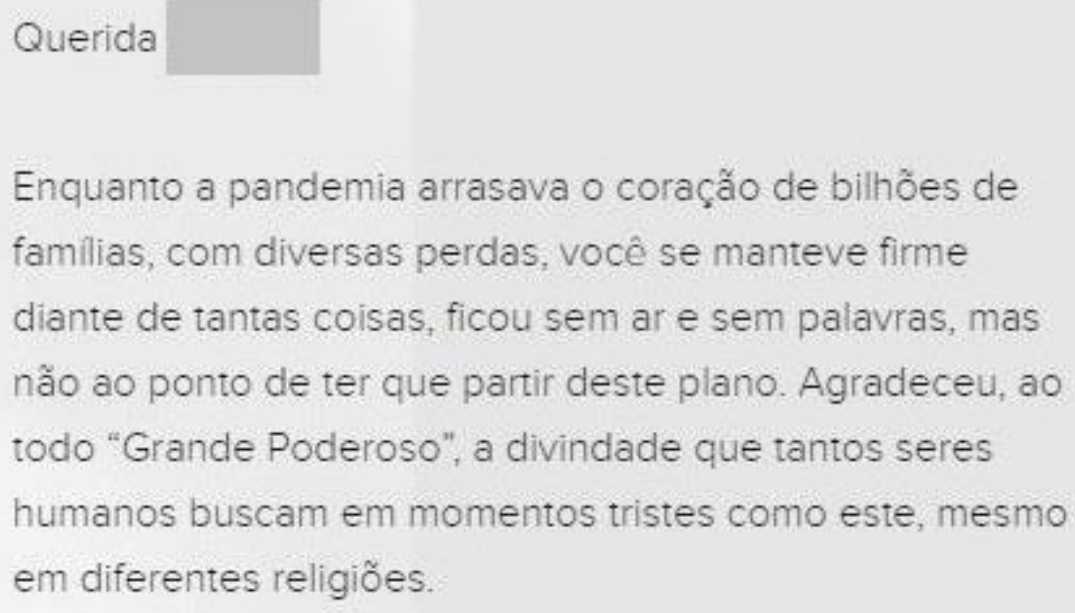

Figura 2. Exemplo de carta para o 'eu do futuro sem coronavírus' Fonte. Blog estudante

No trecho desta carta, percebemos como a autoria se posiciona diante do que fora solicitado: trata-se de uma espécie de simulação de cisão do "eu", a partir da qual um "eu do presente pandêmico" escreve a um "eu do futuro não pandêmico". Além de imaginar uma situação mais amena, a autoria busca 
construir uma reflexão sobre suas próprias ações do presente, considerando sua resiliência diante do inóspito, de maneira a revelar um olhar cuidadoso e até afetuoso, subjetivo, consigo mesmo. Em outras palavras, estamos diante de um texto altamente subjetivo e sincero, no qual um sujeito se posiciona diante do vivido e experenciado de maneira cuidadosa e sincera. Interessante observar ainda que a presença do interlocutor é fundamental, ainda que seja um interlocutor imaginado, pois é esta presença que determina o discurso e a maneira de apresentá-lo.

Muito se discute sobre o caráter artificial das produções escritas dentro da escola. Os textos não circulam, os professores são os únicos leitores, as indicações de escrita são generalistas (sem especificar objetivos, público, tipo de linguagem etc.). As discussões acerca dessa superficialidade têm possibilitado a construção de propostas que visem superar essas questões. Nesse sentido, propusemos, ao final da leitura interlocutiva, que disponibilizássemos os blogs dos alunos para todos da turma. Em resumo, construímos uma lista com os links dos alunos e alunas que se sentiram confortáveis em divulgar o que que haviam produzido. O principal objetivo, claro, era o de oportunizar uma leitura real desses textos. Muitos alunos gostaram da ideia e aceitaram que seus blogs fossem divulgados aos colegas. Importante mencionar, ainda, que antes mesmo dessa divulgação muitos já haviam colocado em prática essa interação real. Na plataforma Instagram, por exemplo, muitos foram seguidos por amigos e colegas de outras turmas que interagiram com eles por meio de "curtidas" ou "comentários".

Diante disso, defendemos neste trabalho que o interlocutor é a base de nossas interações. Seja ele real ou imaginado, é a ele que direcionamos o nosso dizer. Dessa forma, a prática de produção de textos dentro da escola precisa considerar e alinhar essa concepção de interlocução como forma de incentivar que nossos alunos sejam mais autores de seu dizer com base na interação que sempre esperam. Os textos produzidos por nossos alunos precisam circular, mas mais que isso: precisam interagir, pois é a na interação que o sujeito constitui a si e auxilia na constituição do outro.

\section{A prática de Análise Linguística no Blog da Quarentena}

Esperamos que tenhamos deixado claro ao leitor que nosso principal objetivo com essa prática de ensino chamada "Blog da Quarentena" era o de incentivar os alunos a produzirem textos de diferentes gêneros e, ao mesmo tempo, refletirem sobre a situação pandêmica que viviam e vivem. Além disso, acreditamos que a Prática de Análise Linguística poderia ser inserida como uma discussão final desses trabalhos. Para tanto, primeiro fizemos a leitura interlocutiva de todos os trabalhos, avaliamos as produções conforme os critérios pré-definidos, divulgamos os blogs daqueles que gostariam que seus 
blogs fossem lidos pelos demais colegas e, finalmente, propusemos uma aula com discussões de ordem linguística a partir do que fora produzido pelos alunos.

Essa aula de sistematização foi construída a partir da escolha de dois aspectos linguísticos: concordância e utilização de pontuação (especialmente a utilização de vírgula "separando" o sujeito de seu predicado). A escolha desses dois assuntos foi resultado da leitura que fizemos dos trabalhos e da observação que esse era um equívoco que se repetia bastante, especialmente quando o sujeito não é apenas um substantivo. Em outras palavras, nos casos em que o sujeito é uma oração, percebemos que os alunos possuem um pouco de dificuldades de identificar esse sujeito e estabelecer com ele a concordância necessária e, além disso, muitas vezes incluem vírgulas que não deveriam estar ali considerando a ordem canônica do português brasileiro, ou seja, SVO.

Para tanto, a metodologia empregada foi a de: (i) construir uma seleção de pequenos trechos dos textos produzidos pelos alunos que contivessem exemplos desses equívocos; (ii) disponibilizar aos alunos, via Moodle, essa seleção; (iii) solicitar que propusessem melhorias naqueles trechos; (iv) sistematizar, com base nas propostas de melhoria trazidas pelos estudantes, as questões metalinguísticas envolvendo concordância e pontuação. Essa prática metodológica foi pensada para oportunizar aos alunos a autonomia em suas análises ao mesmo passo que possibilitou a estruturação metalinguística do processo. Em outras palavras, a proposta de melhoria das questões de concordância e pontuação não foi um fim em si mesmo, mas resultado de um processo anterior que resultou nessa sistematização.

Com essa prática, percebemos que os estudantes participaram mais efetivamente da construção de conceitos, uma vez que foram construindo, a partir de uma prática lógica e dedutiva, sua própria compreensão do que é proposto pela Gramática Normativa acerca das questões de concordância e pontuação envolvendo o sujeito e seu predicado. Além disso, com a leitura interlocutiva que fizemos, não atribuímos à construção do Blog da Quarentena um caráter de texto de escola, ou seja, incentivamos que os alunos escrevessem porque tinham o que dizer, não para serem corrigidos ou coagidos por sua escrita. Acreditamos, portanto, que esse foi um exemplo interessante de Prática de Análise Linguística de Perspectiva Dialógica.

\section{Considerações Finais}

Este trabalho tratou de um exemplo de prática de ensino permeada pela Prática de Análise Linguística de Perspectiva Dialógica. Buscamos apresentar ao leitor um breve panorama da atividade 
que chamamos de "Blog da Quarentena" que aliou práticas de produção de diferentes gêneros discursivos, de leitura interlocutiva e de análise linguística. Nesse sentido, buscamos oferecer aos alunos uma proposta que os reconhecesse como sujeitos que possuem algo a dizer acerca de sua realidade nesse caso, a realidade pandêmica - ao mesmo passo que nos posicionamos não apenas como a figura da professora que lê e corrige, mas sim um sujeito que lê e interage porque também tem o que dizer nessa relação dialógica.

Nesse sentido, buscamos construir um espaço de compartilhamento dos blogs produzidos pelos alunos, especialmente para que os textos produzidos por eles circulassem, ainda que na forma digital. Essa proposta partiu do pressuposto da importância de revermos a artificialidade da redação escolar, uma vez que muitas vezes o professor é o único leitor e interlocutor dos textos produzidos pelos estudantes.

Por fim, a prática de Análise Linguística proposta levou em consideração dois aspectos linguísticos específicos, a concordância e a utilização da pontuação. A escolha por esses dois aspectos foi resultado da leitura interlocutiva que fizemos, pois observamos nas produções uma dificuldade de identificar um sujeito não nominal, ou seja, um sujeito oracional. Dessa forma, a concordância entre o sujeito e o predicado e a não marcação da ordem canônica foram duas questões bastante problemáticas.

\section{Referências}

BRASIL. Parâmetros Curriculares da Educação Nacional: Língua Portuguesa. Secretaria de Educação Fundamental. Brasilia: MEC, 1997/1998.

BRASIL. Base Nacional Comum Curricular: Educação Infantil e Ensino Fundamental. Brasília: MEC/Secretaria de Educação Básica, 2017.

FRANCHI, C. Mas o que é mesmo "gramática"? In: POSSENTI, S. (Org.). Mas o que é mesmo "gramática"?. São Paulo: Parábola, 2006a [1991]. p. 11- 33.

FRANCHI, C. Criatividade e gramática. In: POSSENTI, S. (Org.). Mas o que é mesmo "gramática"?. São Paulo: Parábola, 2006b [1988]. p. 34-101.

FRANCO, N.; ACOSTA PEREIRA, R.; COSTA-HÜBES, T. C. da. Por uma análise dialógica do discurso. In: GARCIA, D. A.; SOARES, A. S. F. De 1969 a 2019: um percurso da/na análise de discurso. Campinas, SP: Pontes Editores, 2019. p. 275-300.

GERALDI, J. W. (Org.). O texto na sala de aula. 5. ed. São Paulo: Anglo, 2012 [1984].

GERALDI, J. W. Portos de passagem. 2 ed. São Paulo: Martins Fontes, 1997 [1991]. 
OLIVEIRA, N. A. F.; POLATO, A. D. M. Análise Linguística: o funcionamento dialógico-valorativo de recorrências gramaticais na notícia, Polifonia, Cuiaba, v. 22, n. 31, p. 431-461, jan./jun., 2015.

Data de submissão: 08/09/2021. Data de aprovação: 03/11/2021. 